\title{
EVALUATION OF DROPLET SPECTRA OF THE SPRAY TIP AD 11002 USING DIFFERENT TECHNIQUES
}

\author{
João P. A. R. da Cunha ${ }^{*}$, Elton F. dos Reis ${ }^{2}$, Heli H. T. de Assunção ${ }^{3}$, Thiago N. Landim³ \\ ${ }^{1 *}$ Corresponding author. Federal University of Uberlândia/ Uberlândia - MG, Brazil. \\ E-mail: E-mail: jpcunha@ufu.br | ORCID ID: http://orcid.org/0000-0001-8872-3366
}

KEYWORDS
application
technology, droplet
size, water-sensitive
paper, laser
diffraction.

\begin{abstract}
Knowledge of droplet spectra generated by spray nozzle tips is important to ensure the quality of applications of plant protection products. However, there are different methods for this evaluation, which can cause difficulty in interpreting the results. This study aimed to evaluate the droplet spectra produced by the flat fan spray tip AD 11002 operated under different pressures and using different techniques and equipment. The volume median diameter (VMD), percentage of spray volume in droplets smaller than $100 \mu \mathrm{m}$ diameter and relative spam (RS), considering pressures of 200, 300, and $400 \mathrm{kPa}$ were determined using two direct measurement equipment (Spraytec and Shadow Sizer), based on laser diffraction and image analysis, respectively, and a measure based on indirect analysis, through the digitization of water-sensitive paper. Thus, the use of different analysis techniques led to variations of the analyzed parameters. Among the direct measurement equipment, a difference of up to 58\% was observed in VMD. The use of water-sensitive paper to characterize droplet spectra must be carried out with great discretion because there is an underestimation of fine droplets. Pressure variations of 200 to $400 \mathrm{kPa}$ did not influence VMD and RS.
\end{abstract}

\section{INTRODUCTION}

Application technology of plant protection products is determinant for the success of crops. Phytosanitary control, based on plant protection products, depends not only on product effectiveness but also on the correct mode of application (Sasaki et al., 2016; Cunha et al., 2017).

Within application technology, the determination of droplet spectra of a spray has a great influence on the result of an application, being able to estimate the drift, loss to the soil, deposition and target coverage and, consequently, the effectiveness in controlling weeds, pests, and diseases (Guler et al., 2007; Carvalho et al., 2018).

Although some companies that manufacture spray tips disclose in the technical specifications the droplet size ranges as a function of the operating pressures, they are not fixed and can be changed according to the physical characteristics of the spray solution, building machine parameters (air flow), among others (Yan et al., 2017; Carvalho et al., 2017; Carvalho et al., 2018).

In addition to the average droplet size, another important aspect coupled to droplet spectra of a spray tip is the drift risk potential for applications (Matthews, 2004).
Besides representing a loss to the growers, it can cause impacts on human health, food security, and environmental contamination (França et al., 2017; Palardy \& Centner, 2017). Drift can still be cumulative, increasing the selectivity of resistance to commercial molecules, directly affecting the sustainability of applications (Carvalho et al., 2018).

Thus, droplet spectra of spraying are expected to be as uniform as possible to reach the desired target with the droplet density and coverage characteristics, avoiding very coarse or very fine droplets, which can cause runoff or losses by drift, respectively (Cunha et al., 2010). Overall, droplets smaller than $200 \mu \mathrm{m}$ are more likely to drift, and droplets larger than $400 \mu \mathrm{m}$ may lead to runoff, but other factors such as application rate, leaf area index, and meteorological conditions also influence these loss processes (Baesso et al., 2014).

Currently, different particle analysis equipment, with specific operating principles, are adopted for the direct evaluation of droplet spectra of spraying. However, given the high investment necessary to acquire this sophisticated equipment, the use of indirect methods, such as watersensitive papers, is also widely diffused in the field and science. Water-sensitive papers change their coloration

\footnotetext{
${ }^{2}$ State University of Goiás/Anápolis - GO, Brazil.

${ }^{3}$ Federal University of Uberlândia/ Uberlândia - MG, Brazil.

Received in: 2-12-2019

Accepted in: 4-22-2019
} 
when hit by droplets, thus enabling the visual analysis or using specialized computer programs (Halley et al., 2008).

In general, differences can be found between values measured by different equipment (Fritz et al., 2014), although it has not been well characterized in what magnitude. In this sense, droplet size classes, measured from reference spray tips, were created as a way to minimize this problem (Asabe, 2009). It has been a very practical and effective solution for use in the field. However, these classes do not always meet the objectives in scientific research because they allow no differentiation between treatments within the same class. For instance, Hoffmann \& Kirk (2005) observed that two sprayings, classified with medium droplet spectra, generated different drift results. Also, it is sometimes difficult to use the droplet size class scheme when the tip generates curves that cross the boundaries established by reference spray tips.

Therefore, it is often necessary to use numerical values that characterize droplet spectra, such as the volume median diameter (VMD), and, for this, knowing the data generating equipment is essential. In this sense, it is important to verify whether different equipment and techniques for the determination of droplet spectra by direct and indirect methods are similar to each other, as well as the magnitude of the differences in the determined parameters. Thus, this study aimed to evaluate the droplet spectra produced by a flat fan hydraulic spray tip operated under different pressures and using different techniques and equipment.

\section{MATERIAL AND METHODS}

The experiment was initially conducted in a completely randomized design for each of the three techniques for determining the droplet spectra, with three treatments (three operating pressures) and six replications. A flat fan hydraulic spray tip model AD 11002 manufactured by the company MagnoJet ${ }^{\mathbb{R}}$, with a ceramic core, was used in all evaluations. The manufacturer recommends for the tip a pressure range between 200 and $410 \mathrm{kPa}$, and this study was carried out at pressures of 200 , 300 , and $400 \mathrm{kPa}$.

Two techniques of direct measurement of droplet spectra and one of measurement based on the indirect analysis using water-sensitive paper were used. The parameters volume median diameter (VMD, $\mu \mathrm{m}$ ), percentage of spray volume in droplets smaller than $100 \mu \mathrm{m}$ diameter $(\mathrm{V}<100, \%)$, and relative spam (RS, dimensionless) were determined in all analyses, and RS was obtained using [eq. (1)]

$$
\mathrm{RS}=\frac{D_{v 0.9}-D_{v 0.1}}{D_{v 0.5}}
$$

Where,

$D_{v 0.1}$ is the droplet diameter such that $10 \%$ of the sprayed solution volume consists of droplets smaller than that value $(\mu \mathrm{m})$,

$D_{v 0.5}$ is the droplet diameter such that $50 \%$ of the sprayed solution volume consists of droplets smaller than that value (VMD) $(\mu \mathrm{m})$, and

$D_{v 0.9}$ is the droplet diameter such that $90 \%$ of the sprayed solution volume consists of droplets smaller than that value $(\mu \mathrm{m})$.
The determinations in the direct measurement equipment were carried out using the routine methodology used in the laboratory, always with the tip placed at $0.5 \mathrm{~m}$ height from the reading point and so that the measurement counted the droplets crosswise to the produced jet (Guler et al., 2007).

The evaluations of droplet spectra were carried out at the Laboratory of Pesticide Application (LADA), belonging to the Department of Agricultural Engineering of the Federal University of Viçosa, Viçosa, MG, Brazil, using a Spraytec real-time spray particle analyzer (Malvern Instruments Co., Worcestershire, UK), with a focal lens of $750 \mathrm{~mm}$ and set up to account for droplets from 0.10 to 2500 $\mu \mathrm{m}$, with an acquisition rate of $2.5 \mathrm{kHz}$ and a reading time of $1.5 \mathrm{sec}$, as in Maciel et al. (2016). The equipment uses the laser diffraction technique to measure the droplets. The tip was mounted on a mobile structure that allowed the entire jet to crosswise traverse the laser beam during the reading.

The droplet spectra were also obtained at the Laboratory of Prototypes of Agricultural Machinery of the Campus of Exact and Technological Sciences of the State University of Goiás, Anápolis, GO, Brazil, using a Shadow Sizer particle image analyzer (Dantec Dynamics Inc., Skovlunde, Denmark). The characterization was performed in real time by the software Dynamic Studio version 2016, pre-calibrated with a known scale. The system analyzed the droplet spectra from the shadow projected by the particles captured by a camera positioned opposite the light source (LED). The diameter and volume of droplets were identified from the processing of images captured by the camera, a technique called Particle/Droplet Image Analysis (PDIA). Each reading was obtained from the average of 20 images. The digital camera was a FlowSense EO (4 megapixels), 2352 x 1768 pixels and a frequency of 41 frames per second, with Zeiss Rokinon $100 \mathrm{~mm} \mathrm{f/2.8} \mathrm{Macro} \mathrm{Lens.} \mathrm{The} \mathrm{smaller}$ diameter reading was $70 \mu \mathrm{m}$ in the used configuration.

The analysis using water-sensitive paper (76 x 26 $\mathrm{mm}$ ) (Syngenta, Basel, Switzerland) was carried out at the Laboratory of Agricultural Mechanization (LAMEC), linked to the Institute of Agricultural Sciences of the Federal University of Uberlândia (ICIAG-UFU), similarly to Cunha et al. (2017). For this, six papers were placed on a flat, dry surface aligned at the center of the sprayed jet. Applications were carried out at $0.5 \mathrm{~m}$ height using a knapsack sprayer at constant pressure $\left(\mathrm{CO}_{2}\right)$ with a single spray tip, at a speed of $4.0 \mathrm{~km} \mathrm{~h}^{-1}$ determined by the applicator walking. Water-sensitive papers were then scanned (spatial resolution of 1200 non-interpolated dpi with 24-bit color) and analyzed using the computer program StainMaster $^{\circledR}$ (v.1.2.8), specific for this purpose, using the spreading factor routine for this type of paper.

The liquid sprayed in all situations was the water from the supply network, placed in cylindrical reservoirs pressurized with $\mathrm{CO}_{2}$ to maintain a constant pressure. The environmental conditions were monitored during the conduction of the experiment at the three sites, with an air temperature of $25 \pm 3{ }^{\circ} \mathrm{C}$, relative humidity of $55 \pm 5 \%$, and absence of wind and external luminosity. 
For statistical analysis purposes, it was carried out three analysis of variance and then a joint-analysis, involving all the experiments (Pimentel-Gomes, 2000), after observing the magnitudes of the residual mean square of each experiment. The joint-analysis was performed when the ratio between the highest and lowest residual mean squares did not exceed seven (Banzatto \& Kronka, 1992). The experimental design was a completely randomized design in a $3 \times 3$ factorial scheme, with three working pressures and three measurement techniques, with six replications. The data were compared by the Tukey's test at 0.05 significance using the statistical program SISVAR 5.6 (Ferreira, 2014). There was no need to transform the data as a function of the homogeneity of variances and normality of residuals.

\section{RESULTS AND DISCUSSION}

Table 1 shows the VMD evaluated from each measurement technique at different pressures. The interaction between the measurement technique and the pressure was not significant, indicating the independence between factors. In addition, the effect of pressure was not significant. Shadow Sizer equipment generated the lowest VMD, while the measurement using the water-sensitive paper provided the highest VMD. The VMD determined with water-sensitive paper was approximately 2.9 and 1.8 times higher than that determined with Shadow Sizer and Spraytec, respectively. The difference between direct reading equipment was approximately 1.6 times.

TABLE 1. Volume median diameter (VMD, $\mu \mathrm{m})$ of the flat fan spray tip AD 11002, determined with different measurement techniques at pressures of 200,300 , and $400 \mathrm{kPa}$.

\begin{tabular}{|c|c|c|c|c|}
\hline \multicolumn{5}{|c|}{$\operatorname{VMD}(\mu \mathrm{m})$} \\
\hline \multirow{2}{*}{ Measurement technique } & \multicolumn{3}{|c|}{ Pressure $(\mathrm{kPa})$} & \multirow{2}{*}{ Mean between pressures } \\
\hline & 200 & 300 & 400 & \\
\hline Shadow Sizer & 169.4 & 147.6 & 150.3 & $155.8 \mathrm{a}$ \\
\hline Spraytec & 235.9 & 263.0 & 239.1 & $246.0 \mathrm{~b}$ \\
\hline Water-sensitive paper & 460.0 & 451.7 & 455.0 & $455.6 \mathrm{c}$ \\
\hline Mean between techniques & $288.4 \mathrm{~A}$ & $287.4 \mathrm{~A}$ & $281.5 \mathrm{~A}$ & \\
\hline $\begin{array}{lll}\text { CV: } 11.476 & F_{\text {tech: }}: 436.543^{* *} & F_{\text {press: }}: 0.432^{\text {ns }}\end{array}$ & $\mathrm{F}_{\text {tech } \mathrm{xp}}$ & $0.958^{\mathrm{ns}}$ & & \\
\hline
\end{tabular}

Means followed by the same uppercase letters in the row and lowercase letters in the column do not differ from each other by the Tukey's test at $5 \%$ probability. $\mathrm{CV}$ : coefficient of variation; $\mathrm{F}_{\text {tech: }} \mathrm{F}$-value for measurement technique; $\mathrm{F}_{\text {press: }} \mathrm{F}$-value for pressure; $\mathrm{F}_{\text {tech }} \mathrm{x}$ press: $\mathrm{F}$-value for the interaction technique x pressure; $* *$ significant at $1 \%$ probability; ${ }^{\text {ns }}$ not significant.

Using the classification proposed by Asabe S572.1 (Asabe, 2009) and considering the different pressures, the measurement technique based on Shadow Sizer resulted in the fine droplet class, while the Spraytec and watersensitive paper provided medium and very coarse droplet classes, respectively, which also demonstrates the difference between the results.

The Shadow Sizer equipment presents as a principle the measurement based on the processing of images captured by a camera. Spraytec, on the other hand, uses a method based on laser diffraction. This methodological difference may explain the difference found between both direct measurement equipment. Another factor that may have led to the differences found is the sampled region. In the Spraytec equipment, the entire jet crosses the laser beam transversely during the reading. In image-based equipment, if there is no tip or equipment movement structure, there is a focus region that limits the analyzed area (Fritz \& Hoffmann, 2016). Thus, in spray tips with a variation of droplet size along the sprayed jet, such as flat fan spray tips, there may be a greater discrepancy between the analyzed spectra. So it is important to standardize the methodologies.

Tuck et al. (1997) compared the droplet spectra obtained by a Doppler particle analyzer and another by image analysis and concluded that both are important tools for droplet evaluation, but the obtained spectra were different. According to these authors, each equipment has limitations. The equipment based on image analysis is suitable for any liquid and allows calculation of droplet speed. On the other hand, the system based on the Doppler effect is more adequate for spraying at higher flow rates and smaller droplets. Thus, the different measurement techniques can be considered complementary, each one being more suitable for a given situation.

The measurement based on the water-sensitive paper has limitations, such as the difficulty of measuring droplets of smaller size, which may have interfered with the obtained results. Hoffmann \& Hewitt (2005) reported technical limitations for droplet measurements on water-sensitive papers when they are smaller than $50 \mu \mathrm{m}$ because there is not enough liquid to visibly mark the paper. Nascimento et al. (2013) mentioned other factors that may lead to an inadequacy of the measurements on sensitive paper: droplet coalescence, and droplet spreading factor.

According to Nascimento et al. (2013), watersensitive paper can be an essential tool in the field in the comparison of variables (percentage of coverage and droplet per $\mathrm{cm}^{2}$ ) generated by droplets from spray tips. However, according to Baio et al. (2015), this technique does not faithfully represent VMD, RS, and $\mathrm{V}<100$ in most situations, which is in accordance with the data presented in this study.

Regarding the effect of working pressure, VMD variation was not enough for the statistical differentiation. Overall, the magnitude of the droplet size variation with increasing pressure depends on the tip model, which may be higher or lower (Cunha et al., 2004).

Another parameter evaluated was percentage of spray volume in droplets smaller than $100 \mu \mathrm{m}$ diameter (Table 2). This parameter allows for estimating the drift risk potential (DRP) of an application. Because these droplets have a tiny mass, they can easily be carried by the wind away from the target area of treatment (França et al., 2017). 
TABLE 2. Percentage of spray volume in droplets smaller than $100 \mu \mathrm{m}$ diameter $(\mathrm{V}<100, \%)$ of the flat fan spray tip AD 11002 , determined with different measurement techniques at pressures of 200,300 , and $400 \mathrm{kPa}$.

\begin{tabular}{lcccc}
\hline \multicolumn{1}{c}{ Measurement technique } & \multicolumn{3}{c}{$\mathrm{V}<100(\%)$} & Mean between pressures \\
& 200 & 300 & 400 & $20.0 \mathrm{c}$ \\
\hline Shadow Sizer & 16.7 & 20.7 & 22.5 & $8.5 \mathrm{~b}$ \\
Spraytec & 6.5 & 8.1 & 10.9 & $0.2 \mathrm{a}$ \\
Water-sensitive paper & 0.2 & 0.2 & 0.3 & \\
\hline Mean between techniques & & $7.8 \mathrm{~A}$ & $9.7 \mathrm{AB}$ & $11.2 \mathrm{~B}$ \\
\hline $\mathrm{CV}: 34.132 \quad \mathrm{~F}_{\text {tech }}: 82.234^{* *}$ & $\mathrm{~F}_{\text {press }}: 4.128^{* *}$ & $\mathrm{~F}_{\text {tech } \text { press }}: 0.844^{\mathrm{ns}}$ & & \\
\hline
\end{tabular}

Means followed by the same uppercase letters in the row and lowercase letters in the column do not differ from each other by the Tukey's test at $5 \%$ probability. CV: coefficient of variation; $F_{\text {tech: }}$ F-value for measurement technique; Fpress: F-value for pressure; $F_{\text {tech }} \times$ press: $F$-value for the interaction technique x pressure; $* *$ significant at $1 \%$ probability; ${ }^{\text {ns }}$ not significant.

The interaction between the measurement technique and the pressure was not significant, but the effect of the factors measurement technique and pressure was significant. The indirect determination, carried out with water-sensitive paper, in which the highest VMD values were obtained, presented the lowest $\mathrm{V}<100$ values. This result is in accordance with those found by Cunha et al. (2004), who obtained similar results when analyzing flat fan spray tips, in which the variation of $\mathrm{V}<100$ values followed VMD variations inversely. França et al. (2017) also observed a correlation between $\mathrm{V}<100$ and VMD, demonstrating that these values strongly change inversely, in which the addition of one results in a decrease of the other.

Regarding the direct measurement equipment, both presented statistically different results. $\mathrm{V}<100$ is greatly influenced by the equipment capacity to read finer droplets, which are the most difficult to quantify and measure. The equipment manufacturer specification demonstrates that each of them has a distinct value for the lowest read droplet.

Similarly, RS values (Table 3) differed between droplet spectrum analysis techniques. The Shadow Sizer analyzer, which generated the lowest VMD, resulted in a higher RS, indicating lower uniformity of droplet size. Lower RS values are related to higher homogeneity of the droplet population (Maciel et al., 2016). According to Hewitt (1997), these differences between equipment are due to the region of sampling, equipment resolution, and type of sampling, whether temporal (Shadow Sizer) or spatial (Spraytec). In the temporal technique, the sampling and counting of droplets are carried out individually as they pass through the equipment focus region, while the spatial technique presents the sampling of a large number of droplets instantly in a given volume (Fritz et al., 2014).

TABLE 3. Relative spam (RS) of droplet spectra of the flat fan spray tip AD 11002, determined with different measurement techniques at pressures of 200,300 , and $400 \mathrm{kPa}$.

\begin{tabular}{lcccc}
\hline \multicolumn{1}{c}{ Measurement technique } & \multicolumn{2}{c}{ RS } & Mean between pressures \\
& 200 & 300 & 400 & $2.3 \mathrm{c}$ \\
\hline Shadow Sizer & 2.3 & 2.3 & 2.2 & $1.8 \mathrm{~b}$ \\
Spraytec & 1.9 & 1.7 & 1.7 & $1.2 \mathrm{a}$ \\
Water-sensitive paper & 1.2 & 1.2 & 1.3 & \\
\hline Mean between techniques & & $1.8 \mathrm{~A}$ & $1.7 \mathrm{~A}$ & $1.7 \mathrm{~A}$ \\
\hline $\mathrm{CV}: 10.31 \quad \mathrm{~F}_{\text {tech: }} 133.830^{* *}$ & $\mathrm{~F}_{\text {press: }}: 1.933^{\mathrm{ns}}$ & $\mathrm{F}_{\text {tech } \text { press: }}: 1.548^{\mathrm{ns}}$ & & \\
\hline
\end{tabular}

Means followed by the same uppercase letters in the row and lowercase letters in the column do not differ from each other by the Tukey's test at $5 \%$ probability. $\mathrm{CV}$ : coefficient of variation; $\mathrm{F}_{\text {tech: }} \mathrm{F}$-value for measurement technique; $\mathrm{F}_{\text {press: }}$ F-value for pressure; $\mathrm{F}_{\text {tech }} \mathrm{x}$ press: $\mathrm{F}$-value for the interaction technique x pressure; $* *$ significant at $1 \%$ probability; ${ }^{\mathrm{n}}$ not significant.

The water-sensitive paper resulted in the lowest values for $\mathrm{RS}$ and $\mathrm{V}<100$. These results could be positively related to application quality since they would indicate more homogeneous spraying and with lower drift risks. However, when comparing it with the other techniques, the methodology showed to be inconsistent for safe determinations of droplet spectra, mainly regarding fine droplets.

The pressure effect influenced $\mathrm{V}<100$, but did not change RS (Tables 2 and 3). $\mathrm{V}<100$ values varied from $7.8 \%(200 \mathrm{kPa})$ to $11.2 \%(400 \mathrm{kPa})$, being in agreement with data presented by Gandolfo et al. (2014), who showed that an increase in pressure causes an increased drift risk.
As discussed in this study, the different measurement techniques provided different results. In addition to the different measurement principles, droplet sampling also contributed to this result and, in this sense, the standardization of sampling, especially in the case of direct measurements, could minimize this effect.

Hewitt (1997) has shown that different techniques can be considered complementary. Specific advantages of each method allow greater flexibility in measurements under different situations. Techniques based on laser diffraction allow fast measurements of a high number of droplets and high-flow systems, in addition to being able to measure droplets of a wide range of sizes. Systems based on 
image analysis add the measurement of droplet speed and are best suited to measurements under field conditions and very coarse droplets. On the other hand, water-sensitive papers present great applicability in daily evaluations carried out in the field, working as a simple and low-cost tool for the evaluation of application quality. The watersensitive paper use can help the growers to improve their pesticide application.

\section{CONCLUSIONS}

The use of different techniques to analyze droplet spectra of the spray tip AD 11002 resulted in variations of the analyzed parameters, making it difficult the repeatability of the generated data. Among the direct measurement equipment, a difference of up to $58 \%$ was observed in VMD, so it is important to standardize the methodologies to minimize this difference.

The use of water-sensitive paper to characterize droplet spectra is an important tool to improve the pesticide application, but must be carried out with great discretion because there is an underestimation of fine and very fine droplets.

Pressure variations of 200 to $400 \mathrm{kPa}$ for the spray tip AD 11002 did not influence VMD and RS, regardless of the measurement technique.

\section{REFERENCES}

ASABE - American Society of Agricultural and Biological Engineers (2009) Spray nozzle classification by droplet spectra, ANSI/ASAE S572.1. St. Joseph, ASABE, p1-4.

Baesso MM, Teixeira MM, Ruas RAA, Baesso RCE (2014) Pesticide application technologies. Revista Ceres 61(sup):780-785.

Baio FHR, Scarpin IM, Silva EE (2015) Papel hidrossensível e alternativo fotográfico em ensaios de deposição de gotas. Brazilian Journal of Biosystems Engineering 9(4):339-347.

Banzatto DA, Kronka SN (1992) Experimentação Agrícola. Jaboticabal, FUNEP, 247p.

Carvalho FK, Antuniassi UR, Chechetto RG, Mota AAB, Carvalho LD (2017) Viscosity, surface tension and droplets size on spray solutions with formulations of insecticides and fungicides. Crop Protection 101(11):19-23.

Carvalho FK, Antuniassi UR, Chechetto RG, Mota AAB, Carvalho LR (2018) Viscosity, surface tension and droplet size of spray liquids containing formulations of insecticides and fungicides with oil-based adjuvants. Aspects of Applied Biology 137:183-190.

Cunha JPAR, Barizon RRM, Ferracini V, Assalin, M (2017) Spray drift and caterpillar and stink bug control from aerial applications with electrostatic charge and atomizer on soybean crop. Engenharia Agrícola 37(6):1163-1170.
Cunha JPAR, Bueno MR, Ferreira MC (2010) Espectro de gotas de pontas de pulverização com adjuvantes de uso agrícola. Planta Daninha 28(spe):1153-1158.

Cunha JPAR, Teixeira MM, Vieira RF, Fernandes HC, Coury JR (2004) Espectro de gotas de bicos de pulverização hidráulicos de jato plano e de jato cônico vazio. Pesquisa Agropecuária Brasileira 39(10):977-985.

Ferreira DF (2014) Sisvar: a Guide for its Bootstrap procedures in multiple comparisons. Ciência e Agrotecnologia 38(2):109-112.

França JAL, Cunha JPAR, Antuniassi UR (2017) Spectrum, velocity and drift of droplets sprayed by nozzles with and without air induction and mineral oil. Engenharia Agrícola 37(3):502-509.

Fritz BK, Hoffmann WC (2016) Measuring spray droplet size from agricultural nozzles using laser diffraction. Journal of Visualized Experiments 115:e54533.

Fritz BK, Hoffmann WC, Bagley WE, Kruger GR, Czaczyk Z, Henry RS (2014) Measuring droplet size of agricultural spray nozzles - measurement distance and airspeed effects. Atomization and Sprays 24(9):747-760.

Gandolfo MA, Carvalho FK, Chechetto RG, Gandolfo UD, Moraes D (2014) Effect of working pressure at different spray nozzles on drift quantification in wind tunnel. Engenharia Agrícola 34(1):66-73.

Guler H, Zhu H, Ozkan HE, Derksen RC, Yu Y, Krause CR (2007) Spray characteristics and drift reduction potential with air induction and conventional flat-fan nozzles. Transactions of the ASABE 50(3):745-754.

Halley SS, Hofman V, Panigrahi S, Gu H (2008)

Fungicide deposition measurement by spray volume, drop size and sprayer system in cereal grains. Applied Engineering in Agriculture 24(1):15-21.

Hewitt A (1997) Droplet size and agricultural spraying, Part 1: atomization, spray transport, deposition, drift and droplet size measurement technique. Atomization and Sprays 7(3): 235-244.

Hoffmann WC, Kirk IW (2005) Spray deposition and drift from two medium nozzles. Transactions of the Asae 48(1):5-11.

Hoffmann WC, Hewitt AJ (2005) Comparison of three imaging systems for water sensitive papers. Applied Engineering in Agriculture 21(66):961-964.

Maciel CFS, Teixeira MM, Zolnier S, Cecon PR (2016) Droplet spectrum at different vapor pressure deficits. Revista Ciência Agronômica 47(1):41-46. 
Matthews GA (2004) How was the pesticide applied? Crop Protection 23(7):651-653.

Nascimento AB, Oliveira GM, Fonseca ICB, Abi-Saab OJG, Canteri MG (2013) Determinação do tamanho da amostra de papéis hidrossensíveis em experimentos ligados à tecnologia de aplicação. Semina 34(6):2687-2696.

Palardy N, Centnerb TJ (2017) Improvements in pesticide drift reduction technology (DRT) call for improving liability provisions to offer incentives for adoption. Land Use Policy 69:439-444.

Pimentel-Gomes F (2000) Curso de estatística experimental Piracicaba, Degaspari, 477p.
Sasaki RS, Teixeira MM, Fernandes HC, Zolnier S, Maciel, FS, Alvarenga CB (2016) Droplets spectrum of air-assisted boom sprayers under different environmental and operational conditions. Revista Brasileira de Engenharia Agrícola e Ambiental 20(1): 92-96.

Tuck CR, Butler Ellis MC, Miller PCH (1997) Techniques for measurement of droplet size and velocity distributions in agricultural sprays. Crop Protection 16(7):619-628.

Yan X, Zhai Z, Song Z, Shang S, Rao X (2017) Synthesis and properties of polyester-based polymeric surfactants from diterpenic rosin. Industrial Crops and Products 108(1):371-378. 